\title{
Medical school reserves seats for low-income students to increase diversity
}

- Cite as: CMAJ 2018 November 5;190:E1314-5. doi: 10.1503/cmaj.109-5673

Posted on cmajnews.com on Oct. 17, 2018.

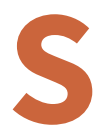
ix students from low-income families who might not have been admitted to the University of Saskatchewan's College of Medicine are on their way to becoming doctors.

Under a new initiative called the Diversity and Social Accountability Admissions Program (DSAAP), 6 of the medical school's 100 seats are reserved for Saskatchewan residents whose household income is less than $\$ 80000$ a year.

The program has been in the works for three years. Dr. Preston Smith, dean of the medical school, said it was proposed in response to literature suggesting the socioeconomic background of the average Canadian medical student does not reflect that of the average Canadian. In 2012, 52\% of medical school students came from households earning more than $\$ 100000$ annually, while only $23 \%$ of Canadian households get over this bar.

Students admitted through DSAAP are first considered in the regular admissions stream. Unsuccessful applicants who indicate their annual family income is less than $\$ 80000$ are reconsidered for the six reserved seats. The program's rollout has been a success, said Smith. Fifty applicants asked to be considered, 37 qualified, and 6 were ultimately admitted. Another six applicants were placed on a waitlist.

"The quality of the students is without question," said Smith.

A diverse medical profession benefits groups that are often underserved, according to Smith, as students from underprivileged or rural communities are more likely to practise in similar communities following graduation, increasing the level of care available in those areas. Lowerincome students also offer unique perspectives that can benefit the student body. "The first thing that they do is bring their own life experience to the class," said Smith.

In August, the medical school received the 2018 ASPIRE-to-Excellence Award in Social Accountability from the Association for Medical Education in Europe in recognition of their commitment to social accountability in medical education. Dean Smith said that DSAAP helped secure the award, along with the school's Indigenous and global health programs.

Dr. Geneviève Moineau, president of the Association of Faculties of Medicine of Canada (AFMC), commended the Univer- sity of Saskatchewan's new initiative. "A program like this in Saskatchewan is an excellent example of a faculty that is taking its social accountability to heart."

Other faculties of medicine across Canada are also focused on improving the diversity of successful applicants, said Moineau. To this end, the AFMC recently created the Future of Admission in Canada Think Tank to help schools increase cultural and socioeconomic diversity among students. But the same solution would be unlikely to work for every school, and each faculty should encourage diversity in a way that fits their unique context, added

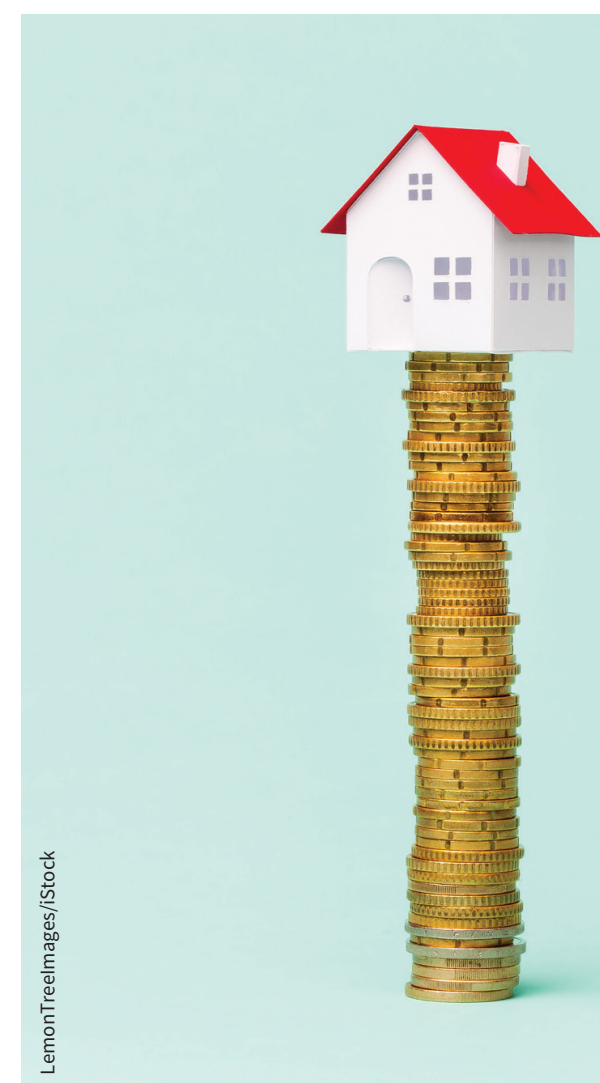

Most medical students come from high-income households. 
Moineau. The University of Calgary's Pathways to Medicine Scholarship and the University of Manitoba's focus on recruiting medical students from Indigenous communities are both examples of how schools can promote diversity through admissions, said Moineau.

According to Stephanie Smith, president of the Canadian Federation of Medical Students, some barriers that prevent lower-income students from entering medical school start long before the admissions process. Students who need to work full- or part-time jobs as under- graduates may have more difficulty getting top grades or building the extensive resume of volunteer work that makes an application competitive. Some students might not be aware of the requirements of a successful application if they aren't in a circle where peers are also applying to medical schools.

The University of Saskatchewan's initiative does a great job of acknowledging that applicants from lower-income families may face unique challenges when applying to medical school, said Stephanie Smith. "It really is demonstrating that we're trying to be inclusive in accepting medical students from a variety of backgrounds."

Medical schools may also want to consider multidimensional approaches that help students with tuition, application fees and the cost of the Medical College Admissions Test, suggested Stephanie Smith. Financial support isn't set aside for DSAAP students, specifically, but they do qualify to apply for scholarships and bursaries offered by the University of Saskatchewan's medical school.

Caroline Mercer, Ottawa, Ont. 